\title{
Fatigue Life of Mooring Lines on External Turret Floating LNG for Different Pretension and Water Depth
}

\author{
Norman Mahdar Sabana ${ }^{1}$, Eko Budi Djatmiko ${ }^{2}$, Rudi Walujo Prastianto ${ }^{3}$
}

\begin{abstract}
This paper studies fatigue life of mooring lines applied on turret-moored Floating LNG (Liquefied Natural Gas). Several case studies were designed to investigate the influence of mooring pretension and water depth on the fatigue life of mooring lines. Floating LNG with permanent external turret mooring system consists of 12 catenary lines arranged in 3 groups with four lines each. Time domain simulation applied to calculated coupled dynamic response and mooring tension. Fatigue life is assessed using the rain-flow counting method, T-N curves, and Palmgren-Miner rule. Analysis results for mooring pretension case show that case study 2 with the lowest pretension (14\% MBL) yields shortest mooring fatigue life of 1814.20 years compared to case study $1(18 \% \mathrm{MBL})$ and $3(22 \% \mathrm{MBL})$ with 2034.61 years and 2983.33 years respectively. Despite having the lowest dynamic line tension, case study 2 has a larger tension range that results in the increased of fatigue damage. The increase in water depth will increase the mooring line length and its weight, so it results in an increase in fatigue damage. It is reflected in case study $5(903 \mathrm{~m}$ water depth), which has shortest mooring fatigue life of 1842.65 years compare to case study $1(602 \mathrm{~m}$ water depth) and $4(301 \mathrm{~m}$ water depth) with 2983.33 years and 3363.62 years respectively.
\end{abstract}

Keywords—Dynamic response Fatigue Life, Mooring tension, Palmgren-Miner, T-N curves.

\section{INTRODUCTION}

$\mathrm{F}$ loating structures have been used widely for oil and gas production in the offshore area. As of November 2013, the number of Floating Production Units (FPUs) operated around the worl stands at 277 units, which $62 \%$ of the total are Floating Production Storage and Offloading-FPSO [1]. Mooring lines are still the most important and economically effective components for station-keeping under environmental loads. Mooring systems must provide such station keeping capability and high global performance to ensure allowable excursions against environmental loads.

Compared to the spread mooring system, a turret moored system has the main advantage that the vessel can rotate around the fixed turret. The vessel can then position itself in such a way that it minimizes the forces acting on the vessel from the environment. Fewer chains and smaller anchors can then be used compared to a traditionally spread mooring system. Variance in the wind, current, and wave loads generate variable motion and tension in the mooring system. Floating Production Unit operated in the same location year by year without regular dry docking for inspection and repair. The gradual accumulation of the variable tension can lead to cumulative fatigue damage on the mooring lines. In between 2001 and 2011, more than twenty (20) mooring incidents have occurred to floating production vessels that moored on-site for a long-term duration (1530years). Among those, at least eight (8) incidents had multiple line damages or system failure, some of them led to vessel drifting [2]. Fatigue considered as one of the reasons of mooring line failure, therefore assessing the fatigue life of mooring systems becomes essential in the modern offshore industry.

Lin and Sayer (2015) [3] studied two types of mooring system design method (coupled Low frequency and fully

${ }^{1}$ Norman M. Sabana, Eko B. Djatmiko, and Rudi W. Prastianto are with Departement of Ocean Engineering, Institut Teknologi Sepuluh Nopember, Surabaya, 60111, Indonesia. E-mail: norman.bana@gmail.com.

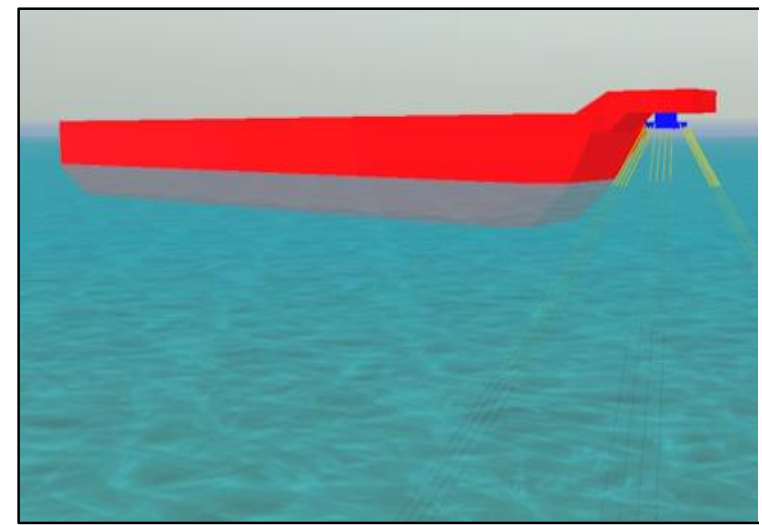

Figure 1. Floating LNG model in OrcaFlex.

coupled) and assessed the behavior of mooring system in different water depth. Both mooring line tension and surge response are entirely determined by the Low frequency (LF) response, particularly for vast water depths.

Wu et al. (2014) [4] presented a numerical analysis of fatigue damage along mooring lines for semisubmersible in the deep water. They identify the most critical fatigue damage locations for different mooring systems. The factors affecting the critical location, such as mooring pattern, pretensions, chain length, water depth are discussed, thus provides recommendations for mooring fatigue design of offshore structures.

Junfeng et al. (2016) [5] studies the effect of several factors on Low frequency (LF) fatigue damage of mooring lines applied in a Semi-Submersible platform. Analytical cases designed to perform fatigue analysis to investigate the influence of water depth, Hs, Tp, and riser system on the fatigue damage of mooring systems.

Kang et al. (2016) [6] studied fatigue analysis of spread mooring line. Contribution of environmental loads (wind, wave, current), type of responses (Wave Frequency and Low-Frequency motions), vessel offsets, mooring position, loading conditions (ballast, intermediate, full) and riser behavior (with and without 
TABLE 1.

VESSEL MAIN PARTICULAR

\begin{tabular}{lc}
\hline \hline Parameter & Value \\
\hline Loa $(\mathrm{m})$ & 430 \\
Breadth $(\mathrm{m})$ & 64 \\
Depth (m) & 38 \\
Displacement (ton) & 371020 \\
Draft (m) - operating & 15.5 \\
VCG (m) - fr keel & 24.4 \\
\hline \hline
\end{tabular}

TABLE 2.

MOORING LINE PROPERTIES

\begin{tabular}{|c|c|c|c|}
\hline Item & $\begin{array}{c}\text { Top } \\
\text { chain }\end{array}$ & S Steel wire & $\begin{array}{c}\text { Bottom } \\
\text { chain }\end{array}$ \\
\hline Type & $\begin{array}{c}\text { Studless } \\
\text { R4 }\end{array}$ & $\begin{array}{c}\text { Spiral strand } \\
\text { sheathed }\end{array}$ & $\begin{array}{c}\text { Studless } \\
\text { R3 }\end{array}$ \\
\hline Diameter (mm) & 157 & 131 & 170 \\
\hline $\operatorname{MBL}(\mathrm{kN})$ & 21234 & 18300 & 19692 \\
\hline Axial stiffness $(\mathrm{kN})$ & 1419594 & 1552000 & 1487895 \\
\hline Weight (ton/m) & 0.487 & 0.0708 & 0.495 \\
\hline
\end{tabular}

riser) are investigated.

The primary purpose of the mooring system is to provide seakeeping and maintain floating structure on position within a specific tolerance, typically based on offset limit. The offset limit can be varying for the various system depends on riser configuration, well position, the existence of another facility in the vicinity of the structure, etc. To provide desirable vessel offset, one can adjust the pretension on the mooring system. Hence, the determination of pretension value has a vital role in the operation of the mooring system. In recent years, the requirements to the mooring and station keeping systems of mobile and permanent units have become more complex. The exploration is moving into new frontiers (deep water). Water depth is recognized as one of the critical parameters in the mooring system design. It will affect mooring line length, material, and configuration.

This paper conduct fatigue analysis on the mooring lines of a Floating LNG (Liquefied Natural Gas) with external turret system. The analysis emphasizes the influence of pretension line and water depth on fatigue life of mooring lines. The various results obtained from these studies can be used as a reference for designing fatigue life of mooring lines with external turret system.

\section{METHOD}

\section{A. Numerical Model}

Barge shaped Floating LNG that permanently moored with an external turret system was selected for this study. The primary particular of the vessel is provided in Table 1 . The mooring system, which consists of 12 mooring lines in 3 groups of 4 lines, is located in front of the vessel's FP (Fore Perpendicular). The angle between mooring lines at the same group is $3 \mathrm{deg}$, while the angle between the groups is $120 \mathrm{deg}$. The mooring lines are made of chain-wire-chain configuration from fairlead to anchor point, respectively. The mooring lines are arranged with $1057.2 \mathrm{~m}$ pattern radius. Mooring line properties are presented in Table 2 .

Vessel and its mooring system are modeled in OrcaFlex, a global static and dynamic analysis program for modeling the behavior of a wide variety of marine and offshore systems. Time domain dynamic analysis performed to simulate moored vessel under

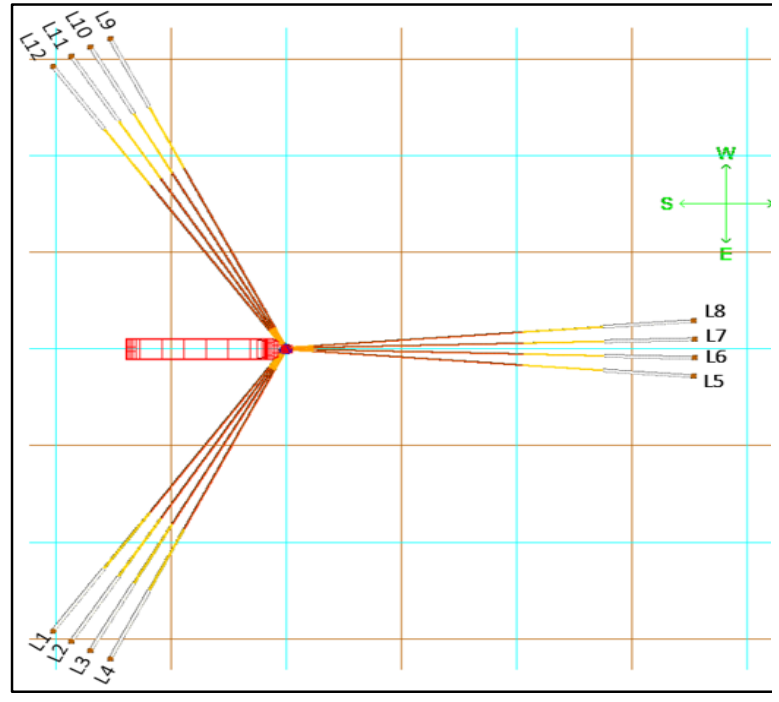

Figure 2. Arrangement of the mooring system.

environmental load case. The main purpose of the dynamic analysis is to obtain mooring line tension for various environmental load case. The model of the vessel with its mooring system is presented in Figure 1 and

Figure 2.

\section{B. Environmental Condition}

Fatigue wave scatters data were adopted from Bangka field located in offshore East Kalimantan, Indonesia. Wave occurrence on the scatter data identified by four variables, i.e., significant wave height (Hs), peak period $(\mathrm{Tp})$, wind speed, and wave direction. Wave and swell scatter data are presented in

\section{Table 3.}

\section{Case Study}

To investigate the influence of pretension line and water depth on the fatigue life of mooring lines, total five (5) case studies are specified. The mooring system configuration for various case studies is summarized in Table 4. Base case or case study 1 is a benchmark, which will be used as a reference to compare the results of other case studies. Case study 2 and three are specified for mooring pretension case. Mooring line pretension will be set to $14 \%$ of Minimum Breaking Loads (MBL) for case study 2 and $22 \% \mathrm{MBL}$ for case study 3 , then will be compared to the pretension of $18 \% \mathrm{MBL}$ (Base case). Case study 4 and five are specified for water depth case. The different values of water depth are $301 \mathrm{~m}, 602 \mathrm{~m}$, and $903 \mathrm{~m}$ for case study 4, 1, and 5, respectively. Mooring system configuration for the specified case study is presented in Table 4.

\section{Fatigue Life Analysis}

Once vessel and its mooring system have been modeled, the static analysis was performed to compute the equilibrium position of the moored structure. Then, dynamic analysis using a time domain approach was performed. This analysis intended to obtain moored structure offset and mooring lines forces. Coupled dynamic analysis performed for each case study. Each case study consists of 83 load cases of dynamic simulations as per wave scatter data.

Tension lines results from the dynamic analysis will 
proceed to obtain fatigue damage on the mooring lines. Fatigue damage of mooring lines is calculated using Rainflow counting method, T-N curves, and PalmgrenMiner rule. T-N curve proposed by API RP 2SK [7] is used for calculating several cycles to failure. Then, Palmgren-Miner rule is used to to calculate the annual cumulative fatigue damage ratio $D$. The annual fatigue damage, accumulated in a mooring line component as a result of cyclic loading, is summed up from the fatigue damage arising in a set of environmental states chosen to discretize the long-term environment that the mooring system is subjected to:
$D=\sum_{i=1}^{i=n} D_{i}$

Where $D i$ is annual fatigue damage to the component due to environmental state $i$. The annual fatigue damage accumulated in an individual state may be computed as:

$D_{i}=\frac{n_{i}}{N_{i}}$

Where $n_{i}$ is the number of tension cycles encountered in state $i$ per year, while $N_{i}$ is several cycles to failure at normalized tension range, $i$ as given by T-N curve. Then, the calculated fatigue life, $L$, of the mooring system is:

$L=\frac{1}{D}$ (years)

TABLE 3.

WAVE SCATTER DATA

\begin{tabular}{|c|c|c|c|c|c|c|c|c|c|c|c|}
\hline \multicolumn{2}{|c|}{ All year } & \multirow{2}{*}{$\begin{array}{l}\text { Wind } \\
(\mathrm{m} / \mathrm{s})\end{array}$} & \multicolumn{8}{|c|}{ Sea wave direction } & \multirow{2}{*}{ All Sea } \\
\hline Hs (m) & $\mathbf{T p}(\mathbf{s})$ & & $\mathbf{N}$ & NE & $\mathbf{E}$ & SE & $\mathbf{S}$ & SW & $\mathbf{W}$ & NW & \\
\hline 0.15 & 3.05 & 4.29 & 0.19 & 0.60 & 0.41 & 0.34 & 0.33 & 0.38 & 0.22 & 0.07 & 2.54 \\
\hline $0.15-0.30$ & 3.35 & 6.06 & 1.55 & 5.27 & 3.83 & 3.47 & 4.61 & 5.60 & 2.02 & 0.9 & 27.25 \\
\hline $0.30-0.45$ & 3.73 & 7.42 & 2.04 & 5.19 & 2.72 & 1.68 & 3.21 & 4.38 & 0.97 & 0.57 & 20.76 \\
\hline $0.45-0.60$ & 3.93 & 8.57 & 2.23 & 4.28 & 1.96 & 0.70 & 1.68 & 2.44 & 0.40 & 0.35 & 14.04 \\
\hline $0.60-0.75$ & 4.24 & 9.58 & 2.36 & 4.17 & 1.69 & 0.29 & 0.53 & 0.79 & 0.18 & 0.14 & 10.15 \\
\hline $0.75-0.90$ & 4.58 & 10.50 & 2.15 & 3.47 & 1.35 & 0.11 & 0.13 & 0.19 & 0.08 & 0.06 & 7.54 \\
\hline $0.90-1.05$ & 4.77 & 11.34 & 1.96 & 2.90 & 1.19 & 0.05 & 0.02 & 0.02 & 0.03 & 0.02 & 6.19 \\
\hline $1.05-1.20$ & 4.90 & 12.12 & 0.98 & 1.39 & 0.59 & 0.01 & 0.00 & 0.00 & 0.01 & 0.00 & 2.98 \\
\hline $1.20-1.35$ & 5.38 & 12.86 & 0.62 & 0.84 & 0.38 & 0.01 & 0.00 & 0.00 & 0.00 & 0.00 & 1.85 \\
\hline $1.35-1.50$ & 5.56 & 13.55 & 0.13 & 0.18 & 0.08 & 0.00 & 0.00 & 0.00 & 0.00 & 0.00 & 0.39 \\
\hline $1.50-1.65$ & 6.05 & 14.22 & 0.05 & 0.06 & 0.03 & 0.01 & 0.01 & 0.01 & 0.00 & 0.00 & 0.17 \\
\hline $1.65-1.80$ & 6.35 & 14.85 & 0.02 & 0.04 & 0.01 & 0.00 & 0.00 & 0.00 & 0.00 & 0.00 & 0.07 \\
\hline $1.80-1.95$ & & & 0.00 & 0.00 & 0.00 & 0.00 & 0.00 & 0.00 & 0.00 & 0.00 & 0.00 \\
\hline 1.95 & & & 0.00 & 0.00 & 0.00 & 0.00 & 0.00 & 0.00 & 0.00 & 0.00 & 0.00 \\
\hline \multicolumn{2}{|c|}{ Subtotal } & & 14.28 & 28.39 & 14.24 & 6.67 & 10.52 & 13.81 & 3.91 & 2.11 & 93.93 \\
\hline \multicolumn{2}{|c|}{ All year } & Wind & \multicolumn{8}{|c|}{ Sea wave direction } & \multirow{2}{*}{ All Sea } \\
\hline Hs (m) & $\operatorname{Tp}(\mathrm{s})$ & $(\mathrm{m} / \mathrm{s})$ & $\mathrm{N}$ & $\mathrm{NE}$ & $\mathrm{E}$ & SE & S & SW & W & NW & \\
\hline 0.15 & 9.67 & 0.00 & 0.00 & 1.70 & 0.00 & 0.00 & 0.00 & 0.00 & 0.00 & 0.00 & 1.70 \\
\hline $0.15-0.30$ & 9.74 & 0.00 & 0.00 & 2.17 & 0.00 & 0.00 & 0.00 & 0.00 & 0.00 & 0.00 & 2.17 \\
\hline $0.30-0.45$ & 9.50 & 0.00 & 0.00 & 0.05 & 0.00 & 0.00 & 0.00 & 0.00 & 0.00 & 0.00 & 0.05 \\
\hline 0.15 & 11.64 & 0.00 & 0.00 & 0.15 & 0.00 & 0.00 & 0.00 & 0.00 & 0.00 & 0.00 & 0.15 \\
\hline $0.15-0.30$ & 12.02 & 0.00 & 0.00 & 1.76 & 0.00 & 0.00 & 0.00 & 0.00 & 0.00 & 0.00 & 1.76 \\
\hline $0.30-0.45$ & 12.22 & 0.00 & 0.00 & 0.25 & 0.00 & 0.00 & 0.00 & 0.00 & 0.00 & 0.00 & 0.25 \\
\hline \multicolumn{11}{|c|}{ Total } & 100.00 \\
\hline
\end{tabular}

TABLE 4.

MOORING SYSTEM CONFIGURATION

\begin{tabular}{llllll}
\hline \hline \multirow{2}{*}{ Description } & \multicolumn{5}{c}{ Case study } \\
\cline { 2 - 6 } & \multicolumn{1}{c}{$\mathbf{1}$} & \multicolumn{1}{c}{$\mathbf{2}$} & \multicolumn{1}{c}{$\mathbf{4}$} & \multicolumn{1}{c}{$\mathbf{5}$} \\
\hline Notes & Base case & $\begin{array}{l}\text { Pretension } \\
14 \% \mathrm{MBL}\end{array}$ & $\begin{array}{l}\text { Pretension } \\
22 \% \mathrm{MBL}\end{array}$ & $\begin{array}{l}50 \% \text { water } \\
\text { depth }\end{array}$ & $\begin{array}{l}150 \% \text { water } \\
\text { depth }\end{array}$ \\
Pretension & $18 \% \mathrm{MBL}$ & $2600 \mathrm{kN}$ & $4040 \mathrm{kN}$ & $3385 \mathrm{kN}$ & $3385 \mathrm{kN}$ \\
& $3385 \mathrm{kN}$ & & & & \\
Water depth & $602 \mathrm{~m}$ & $602 \mathrm{~m}$ & $602 \mathrm{~m}$ & $301 \mathrm{~m}$ & $903 \mathrm{~m}$ \\
Top chain length & $100.0 \mathrm{~m}$ & $123.8 \mathrm{~m}$ & $86.6 \mathrm{~m}$ & $50.0 \mathrm{~m}$ & $150.0 \mathrm{~m}$ \\
Wire rope length & $725.0 \mathrm{~m}$ & $725.0 \mathrm{~m}$ & $725.0 \mathrm{~m}$ & $362.5 \mathrm{~m}$ & $1087.5 \mathrm{~m}$ \\
Bottom chain length & $458.0 \mathrm{~m}$ & $458.0 \mathrm{~m}$ & $458.0 \mathrm{~m}$ & $229.0 \mathrm{~m}$ & $687.0 \mathrm{~m}$ \\
\hline \hline
\end{tabular}

\section{RESULTS AND DISCUSSION}

Tension fatigue analysis is performed to estimate the fatigue life of the major mooring components, such as top chain, steel wire, and bottom chain. It is worth mentioning that refer to API RP 2SK, the T-N curve of steel wire is significantly less severe than the T-N curve of mooring chain. Consequently, for similar tension range, the damage caused in the mooring chain is significantly higher. Therefore, the critical components in this mooring system are the chain segments.

\section{A. Pretension Case}

Mooring line tension and turret offset results from global vessel analysis for pretension case are presented in

Table 5. The results are summarized for the highest tension from all calculated load case. Most tensioned line occurred at line 6 under load case no.77 with $\mathrm{Hs}=1.725 \mathrm{~m} ; \mathrm{Tp}=6.35 \mathrm{~m} ; \mathrm{Vw}=14.85 \mathrm{~m} / \mathrm{s} ; \mathrm{Vc}=0.68 \mathrm{~m} / \mathrm{s}$.

TABLE 5 .

MOORING LINE LOAD - PRETENSION CASE

\begin{tabular}{ccc}
\hline \hline Case study & Tension $(\mathbf{k N})$ & Max. offset radius $(\mathbf{m})$ \\
\hline 1 & 3898.7 & 13.3 \\
2 & 3128.6 & 21.3 \\
3 & 4437.8 & 9.7 \\
\hline \hline
\end{tabular}

Case study 3 with the pretension of $22 \%$ MBL, yields the highest line tension of $4437.8 \mathrm{kN}$ followed with case study 1 and case study 2 with line tension of $3898.7 \mathrm{kN}$ and $3128.6 \mathrm{kN}$, respectively. An increase in pretension for $4 \%$ will increase the dynamic line tension by $14 \%$ from initial dynamic tension, while a $4 \%$ decrease of pretension will reduce the dynamic line tension by $20 \%$ from initial dynamic tension. A $4 \%$ increase in a 
pretension will reduce the horizontal excursion by $37 \%$ from its initial excursion, while a $4 \%$ decrease of pretension will increase horizontal excursion by $60 \%$ from its initial excursion.

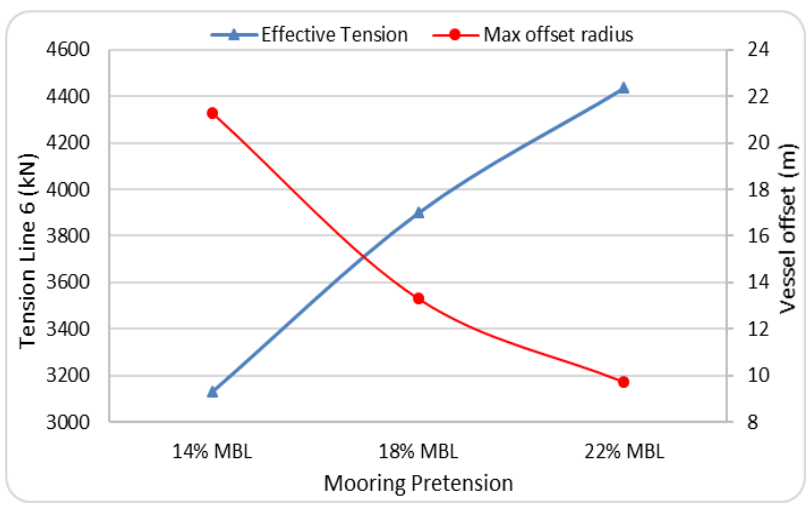

Figure 3. Maximum line tension and vessel offset for different pretension.

The higher mooring line pretension will lead to higher dynamic tension of the line. On the contrary, the higher mooring line pretension will reduce vessel offset since the excursion of the vessel will be limited by the high restoring force of mooring lines. Figure 3 presents the correlation between the tension line and vessel offset for different pretension line.

A comparison between the results of fatigue base case and pretension case are presented in Figure 4.

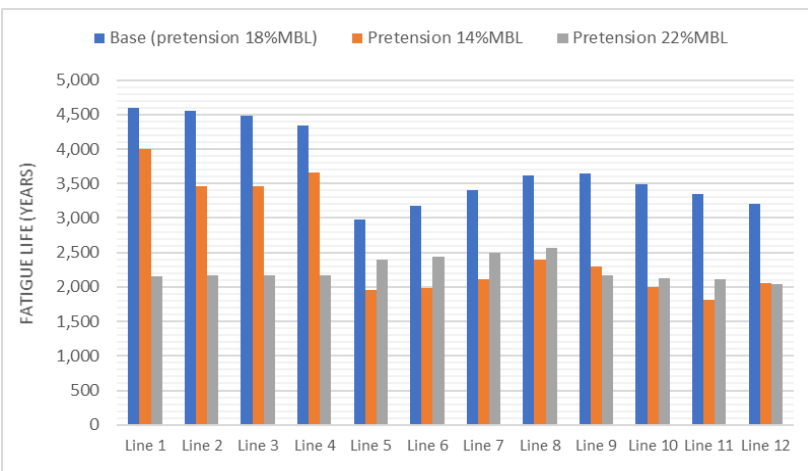

Figure 4. Mooring line fatigue life for different pretension.

Base case (18\% MBL of pretension) yields much longer fatigue life than case study 2 (14\%MBL of pretension) and case study 3 (22\%MBL of pretension). Case study 2 has the shortest fatigue life of 1814.2 years, followed by case study 3 and case study 1 with 2034.61 years and 2983.33 years, respectively. Detailed minimum fatigue life for each pretension condition are presented in Table 6.

TABLE 6.

MiNIMUM FATIGUE LIFE OF MOORING LINE FOR DIFFERENT PRETENSION

\begin{tabular}{cccc}
\hline \hline Case study & $\begin{array}{c}\text { Fatigue life } \\
\text { (years) }\end{array}$ & $\begin{array}{c}\text { Fatigue } \\
\text { damage }\end{array}$ & $\begin{array}{c}\text { Tension } \\
\text { STD }\end{array}$ \\
\hline 1 & 2983.33 & $3.35 \mathrm{E}-04$ & 50.58 \\
2 & 1814.20 & $5.51 \mathrm{E}-04$ & 52.09 \\
3 & 2034.61 & $4.91 \mathrm{E}-04$ & 51.23 \\
\hline \hline
\end{tabular}

It is interesting to note that, despite has the lowest tension, case study 2 has the highest fatigue damage (shortest fatigue life). Smaller pretension will cause larger vessel's offset since the mooring line tends to be in slack position. The larger vessel offset could lead to a larger tension range of mooring line during the simulation. Tension range distribution during the simulation period represented by the standard deviation (STD), where a bigger value of STD indicates larger tension distribution. Mooring line fatigue life decreases due to the increase in line tension STD as vessel offset increases. Therefore, the determination of pretension will affect the fatigue life of mooring lines during operation.

\section{B. Water Depth Case}

Mooring line tension and turret offset results from global vessel analysis for pretension case are presented in Table 7. The results are summarized for the highest tension from all calculated load case. Most tensioned line occurred at line 6 under load case no.77 with $\mathrm{Hs}=1.725 \mathrm{~m} ; \mathrm{Tp}=6.35 \mathrm{~m} ; \mathrm{Vw}=14.85 \mathrm{~m} / \mathrm{s} ; \mathrm{Vc}=0.68 \mathrm{~m} / \mathrm{s}$.

TABLE 7.

MOORING LINE LOAD - WATER DEPTH CASE

\begin{tabular}{ccc}
\hline \hline Case study & Tension $(\mathbf{k N})$ & Max. offset radius $(\mathbf{m})$ \\
\hline 1 & 3898.7 & 13.3 \\
4 & 2432.3 & 10.1 \\
5 & 5198.1 & 13.5 \\
\hline \hline
\end{tabular}

Case study 5 with $903 \mathrm{~m}$ water depth yields the highest line tension of $5198.1 \mathrm{kN}$ followed with case study 1 and case study 4 with line tension of $3898.7 \mathrm{kN}$ and $2432.3 \mathrm{kN}$, respectively. An increase in water depth for $50 \%$ will increase the dynamic line tension by $33 \%$ from initial dynamic tension, while a $50 \%$ decrease of water depth will reduce the dynamic line tension by $38 \%$ from initial dynamic tension. The vessel experienced maximum horizontal excursion of $13.5 \mathrm{~m}$ for case study 5 , followed by case study 1 and case study 4 with $13.3 \mathrm{~m}$ and $10.1 \mathrm{~m}$, respectively. An increase in water depth for $50 \%$ will increase the horizontal excursion by $2 \%$ from its initial excursion, while a $50 \%$ decrease of water depth will decrease the horizontal excursion by $24 \%$ from its initial excursion. Figure 5 presents the correlation between the tension line and water depth change.

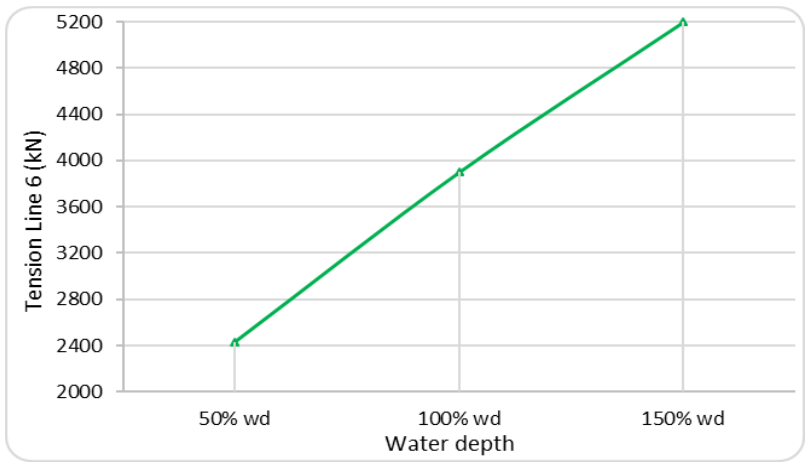

Figure 5. Maximum tension for different water depth.

The higher water depth will increase the mooring line length that leads to an increase in its weight. The increase in mooring line length will give additional drag force on the line that leads to higher tension on the line. Furthermore, the increase in the weight of the mooring line will increase the pretension, where the increase in a pretension will lead to higher dynamic tension on the line. Comparison results of fatigue base case and water depth case are presented in Figure 6.

The most critical fatigue life for different water depth 
occurs in case study 5 with $903 \mathrm{~m}$ water depth. While case study 4 with $301 \mathrm{~m}$ water depth yields the longest fatigue life. Case study 5 has the shortest fatigue life of 1842.65 years, followed by case study 1 and 4 with 2983.33 years and 3363.62 years, respectively.

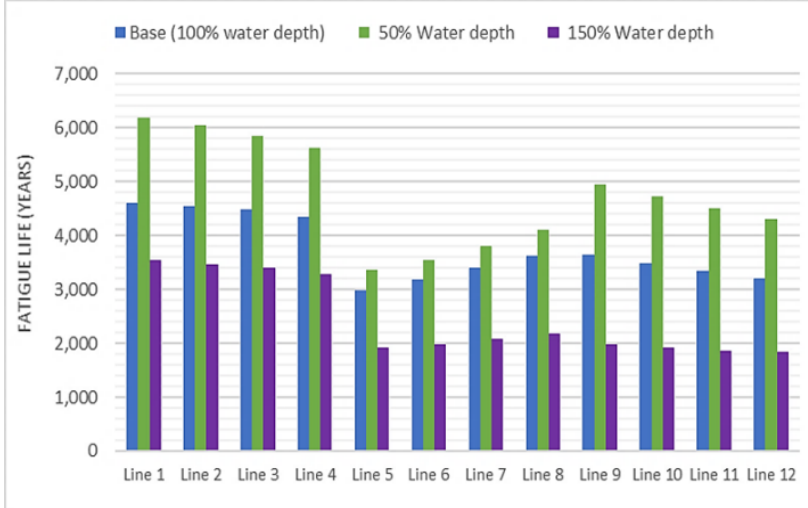

Figure 6. Mooring line fatigue life for different water depth.

Table 8 shows the minimum fatigue life for different water depth. Mooring line fatigue life decrease due to the increase in line tension STD as water depth increases. An increase in water depth for $50 \%$ will reduce the fatigue life of mooring line up to $38 \%$, while a $50 \%$ decrease of water depth will increase the fatigue life of mooring line up to $13 \%$.

TABLE 8.

Minimum FATIGUE LiFE OF MOORING LiNE FOR DIFFERENT WATER DEPTH

\begin{tabular}{cccc}
\hline \hline Case study & $\begin{array}{c}\text { Fatigue life } \\
\text { (years) }\end{array}$ & $\begin{array}{c}\text { Fatigue } \\
\text { damage }\end{array}$ & Tension STD \\
\hline 1 & 2983.33 & $3.35 \mathrm{E}-04$ & 50.58 \\
4 & 3363.62 & $2.97 \mathrm{E}-04$ & 45.34 \\
5 & 1842.65 & $5.43 \mathrm{E}-04$ & 56.02 \\
\hline \hline
\end{tabular}

\section{CONCLUSION}

This paper investigates several parameters which could affect the fatigue life of mooring lines by setting up a series of a case study for a Floating LNG with an external turret mooring system. Based on the numerical results and discussions, the following conclusion can be made as follows:
1. Mooring system with smaller pretension has lower dynamic line tension. However, the smaller pretension leads to larger vessel offset and smaller mooring stiffness. This will increase the tension range and standard deviation (STD) that lead to higher fatigue damage (shorter fatigue life).

2. In the deeper water depth, the weight of the mooring line will increase due to increases in mooring line length that will be followed by increases in pretension. The increase in mooring length will also give additional drag force on the line. This increase will lead to an increase in effective and mean tension. In term of fatigue life, the higher water depth will reduce the fatigue life in the mooring system.

\section{ACKNOWLEDGMENTS}

The authors appreciate Mr. Cecep Hendra, Mr. Agus Budi, Mr. Fajar, and the team from PT. ZEE Engineering Indonesia for the guidance and discussions on the work. The authors would like to thank Noble Denton Indonesia for the support of this study.

\section{REFERENCES}

[1] Offshore Magazine, "Available FPU count at an all-time high," Offshore Magazine, 2013.

[2] K. Ma, A. Duggal, P. Smedley, and H. L'Hostis, D., \& Shu, "A Historical review on integrity issues of permanent moring systems," in Offshore Technology Conference 24025, 1993.

[3] Z. Lin and P. Sayer, "Influence of water depth variation on the hydrodynamics of deep-water mooring characteristics," Ocean Eng. Elsevier, vol. 109, pp. 553-566, 2015.

[4] Y. Wu, T. Wang, O. Eide, and K. Haverty, "Governing factor and locations of fatigue damage on mooring lines of floating structures," Ocean Eng., vol. 96, pp. 109-124, 2015.

[5] D. Junfeng, W. Shuqing, C. Anteng, and L. Huajun, "An investigation on low-frequency fatigue damage of mooring lines applied in a semi-submerssible platform," J. Ocean Univ. China, 2016.

[6] C. Kang, C. Lee, S. H. Jun, and Y. T. Oh, "Fatigue analysis of spread mooring line," Int. J. Environ. Chem. Geol. Geophys. Eng. vol. 10 , no. 5,2016

[7] API RP 2SK, Design, and analysis of stationkeeping systems for floating structures. Washington, D.C.: American Petroleum Institute, 2008. 